\title{
Ensino de Leitura de Sentenças: Contribuições da Análise do Comportamento ${ }^{1}$
}

\author{
Verônica Bender Haydu² \\ Ana Carolina Zuanazzi \\ Universidade Estadual de Londrina \\ Grauben José Alves de Assis \\ Olvia Misae Kato \\ Universidade Federal do Pará
}

\begin{abstract}
RESUMO - O paradigma da equivalência de estímulos tem sido pouco usado para estudar o ensino de leitura de sentenças. Assim, o presente estudo avaliou o efeito de um procedimento de ensino e testes de relações condicionais seguidos pelo encadeamento de palavras sobre a leitura com compreensão de sentenças e a generalização de leitura. Participaram oito escolares, com 7 e 9 anos de idade. O procedimento incluiu pré e pós-teste, três fases de ensino e testes de leitura com compreensão, um teste de conectividade e um teste de construção de sentenças. A leitura de palavras e de sentenças melhorou do pré para o pós-teste em todos os casos, demonstrando que o procedimento foi efetivo para ensinar leitura com compreensão de sentenças.
\end{abstract}

Palavras-chave: equivalência de estímulos, leitura de sentenças, encadeamento, escolha-de-acordo-com-modelo, escolares

\section{Teaching of Sentence Reading: Contributions of Behavior Analysis}

\begin{abstract}
The stimulus equivalence paradigm has been used infrequently in studies of sentence reading. Therefore, the present study evaluated the effect of a procedure involving teaching and testing conditional relations followed by the chaining of words upon sentence reading with comprehension and reading generalization. Eight students, 7 to 9 years old, participated in the study. The procedure included a pre- and post-test, three teaching phases and reading with comprehension tests, a connectivity test, and a sentence construction test. Words and sentences reading improved from pre- to post-test in all cases, showing that the procedure was effective in teaching sentence reading with comprehension.
\end{abstract}

Keywords: stimulus equivalence, sentence reading, chaining, matching-to-sample, scholars.

Investigações sobre processos de aprendizagem como a leitura têm sido desenvolvidas por pesquisadores de diferentes áreas de estudos, incluindo a área da Psicologia. Nessa área, encontram-se estudos publicados por analistas do comportamento que focalizaram o ensino de leitura de palavras, baseados no responder relacional derivado equivalência de estímulos (de Rose, Souza, \& Hanna, 1996; Sidman \& Cresson, 1973; Stromer, Mackay, \& Stoddard, 1992). No entanto, é importante destacar que a leitura de palavras não é suficiente para que um indivíduo efetivamente compreenda textos escritos, sendo a leitura de sentenças uma condição fundamental para que essa compreensão ocorra, conforme sugeriram Ponciano e Moroz (2012).

$\mathrm{O}$ ensino de leitura de sentenças/frases com base no modelo da equivalência de estímulos foi objeto de estudos desenvolvidos por Medeiros et al. (2011), Ponciano e Moroz (2012), e Sampaio, Assis e Baptista (2010), dentre outros. Medeiros et al. (2011) demonstraram que ensinar separadamente os comportamentos de ler e escrever

1 Apoio: CNPq e Fundação Araucária

2 Endereço para correspondência: Departamento de Psicologia Geral e Análise do Comportamento, Universidade Estadual de Londrina, Rod. Celso Garcia Cid, Km 380, Campus Universitário, Londrina, PR, Brasil, Caixa Postal 10011. CEP: 86.057-970.E-mail: haydu@uel.br palavras substantivadas, números e numerais, e nomes de cores promoveu leitura com compreensão de frases curtas formadas por três classes de estímulos (por exemplo, "Sete potes vermelhos", p. 323), em 9 de 11 participantes, os quais apresentaram altas porcentagens de acerto (acima de 90\%). Os resultados permitiram concluir que houve a emergência de leitura com compreensão, por meio do ensino prévio das unidades que compõem as frases e do agrupamento dessas unidades.

O agrupamento de palavras pode ser considerado um pré-requisito da leitura de textos, mas pode não ser suficiente para a leitura com compreensão de sentenças completas. As frases do estudo de Medeiros et al. (2011), por exemplo, não continham o verbo, não se caracterizando como um período completo, aspecto que ainda requer ser investigado, conforme sugestão dos próprios autores. Outro pré-requisito que vem sendo investigado é o responder sequencial, em que a ordem dos eventos tem a função de controle de estímulos. O responder sequencial, segundo Assis, Baptista e Nunes (2009), pode ser estabelecido por meio de inferência transitiva, da formação de sequências em contingência tríplice, do controle condicional e da transferência de desempenhos de escolha de acordo com o modelo (do inglês, matching to sample-MTS) para classes sequenciais. Esses autores destacaram a proposta de Green, Stromer e Mackay (1993), os quais explicaram a inferência transitiva com base em relações entre os componentes das 
sequências de estímulos do tipo ordinal, envolvendo as propriedades de irreflexividade, assimetria, transitividade e conectividade (descritas no próximo parágrafo), as quais são comprovadas por meio de testes. Esses testes demonstram o controle de estímulos no responder sequencial.

Representações alfanuméricas para os estímulos (por exemplo, A1, A2 etc.) e uma seta $(\longrightarrow)$ para a relação de ordem foram propostos por Green et al. (1993), de tal forma que uma sequência com quatro estímulos, por exemplo, é representada por $\mathrm{A} 1 \longrightarrow \mathrm{A} 2 \longrightarrow \mathrm{A} 3 \longrightarrow \mathrm{A} 4$. Após o ensino de ordenação são testadas as propriedades de irreflexividade, assimetria, transitividade e conectividade, por meio de recombinações dos estímulos em contingências de três termos, sem reforços diferenciais para as respostas. A propriedade "irreflexividade" caracteriza relações ordinais como não reflexivas, isto é, relações em que um elemento não pode ser seguido por ele mesmo. A propriedade da assimetria caracteriza a relação ordinal como unidirecional. Dessa forma, se A2 $\rightarrow$ A3 é verdadeira, então A3 $\rightarrow$ A2 não é. A propriedade denominada transitividade caracterizase por ser considerada correta a relação $\mathrm{A} 2 \longrightarrow \mathrm{A} 4$, tendo sido estabelecidas as relações $\mathrm{A} 2 \longrightarrow \mathrm{A} 3$ e A3 $\rightarrow$ A4, e um elemento estiver ausente, por exemplo, A3. A transitividade envolve pares não adjacentes da série. "Finalmente, se $\mathrm{A} 1 \longrightarrow \mathrm{A} 2 \longrightarrow \mathrm{A} 3$, então $\mathrm{A} 1 \longrightarrow \mathrm{A} 2, \mathrm{~A} 1 \longrightarrow \mathrm{A} 3 \mathrm{e} \mathrm{A} 2 \longrightarrow \mathrm{A} 3$, ou seja, é verdadeira a relação denominada conectividade entre todos os pares possíveis" (Assis et al., 2009, p. 217).

Assis et al. (2009) revisaram sete estudos (Assis \& Costa, 2004; Assis \& Sampaio, 2003; Lima \& Assis, 2003; Nunes \& Assis, 2006 Sampaio \& Assis, 2005; J. A. N. Souza \& Assis, 2005; R. D. C. Souza \& Assis, 2005), os quais envolveram procedimentos de encadeamento ou de sobreposição de estímulos e, subsequentemente, a aplicação dos testes de irreflexividade, assimetria, transitividade e conectividade. Os resultados dos estudos levaram Assis et al. (2009) a concluir que a ordem tem uma direção definida a partir de características ou dimensões dos estímulos, como a numerosidade, o tamanho, e a forma, podendo essas ser crescentes ou decrescentes. A ordem remete à relação entre eventos antecedentes e consequentes, sendo um exemplo a formação de classes sintáticas, em que a disposição das palavras em uma frase seguem uma determinada ordem, estabelecida pela comunidade verbal para que a frase tenha sentido.

Um procedimento envolvendo encadeamento de respostas, testes de produção de sentenças e testes de conectividade, para demonstrar a leitura com compreensão de palavras e de sentenças, foi desenvolvido por Sampaio Assis e Baptista (2010). Nesse estudo, os autores compararam o desempenho de participantes que foram submetidos aos procedimentos de treino de discriminação condicional e de formação de classes de equivalência ao de participantes que não foram submetidos a esses dois procedimentos antes do encadeamento das palavras. Todos os participantes foram capazes de construir sentenças novas. "A posição que cada palavra ocupava na linha de base (artigo, substantivo, verbo e advérbio) parece ter exercido uma função de ordem muito explicitamente na composição das novas sentenças, garantindo uma leitura fluente e com compreensão" (p. 154). No entanto, os participantes que não foram submetidos ao treino de discriminação condicional e aos testes de equivalência com palavras compuseram as seis novas sentenças, mas não foram capazes de fazer uma leitura fluente. Esses dados permitem destacar a importância de as palavras terem significado para o leitor para que uma leitura fluente e com compreensão possa ser observada.

Diferentemente de Sampaio et al. (2010) e de Medeiros et al. (2011), Ponciano e Moroz (2012) consideraram que o ensino de frases poderia ser feito por meio do ensino de relações condicionais entre estímulos, tomando as frases como unidades de ensino. Nesse caso, foram ensinadas relações condicionais entre frases ditadas e cenas impressas representativas das frases, e entre frases ditadas e frases impressas. Participaram três crianças que inicialmente não liam frases e que frequentavam a escola por, no mínimo, cinco anos. Apenas dois dos três participantes concluíram todas as fases do procedimento e apresentaram, após o procedimento de ensino, emergência de leitura das frases de ensino. Um desses dois participantes demonstrou mais de $80 \%$ de acertos nos testes de leitura de sentenças de generalização e no teste de manutenção.

Os resultados de Medeiros et al. (2011), de Ponciano e Moroz (2012) e de Sampaio et al. (2010) são bastante promissores em relação ao ensino de leitura com compreensão de sentenças por meio do modelo da equivalência de estímulos e do treino de encadeamento. No entanto, permanecem questões a serem respondidas. Por exemplo, como ensinar a leitura de sentenças em que mudanças no sentido das palavras ocorrem devido à alteração da ordem delas na frase, como acontece com sentenças na voz passiva em comparação a sentenças na voz ativa? Corrêa, Assis e Brino (2012) propuseram que o controle condicional estabelecido pela modalidade da voz ao proferir as palavras nas sentenças poderia ser um procedimento apropriado para esse ensino. Outra questão é como ensinar sentenças em que apenas a terminação de uma palavra é alterada e a sentença tem seu significado modificado, como acontece com as conjugações de verbos?

Essas questões nortearam o desenvolvimento do presente estudo, no qual foi proposta uma sequência de etapas de procedimento baseada em Ponciano e Moroz (2012) e em Sampaio et al. (2010). Essa sequência envolveu: (a) o treino de relações condicionais entre estímulos que podem resultar na formação de classes de equivalência das palavras faladas, palavras impressas e figuras; (b) o treino de encadeamento que pode promover a formação de classes ordinais; (c) o treino de relações condicionais entre sentenças faladas, sentenças escritas e animações, representando a cena da sentença e (d) o teste de conectividade (produção de sentenças novas). As sentenças ensinadas estavam no plural e no singular, e em três tempos verbais (presente, passado e futuro), sendo cada uma delas representada por uma animação (gif). Assim, o presente estudo analisou o efeito de uma sequência de etapas de ensino e de testes de relações condicionais, bem como do encadeamento de palavras, sobre a leitura com compreensão das sentenças no presente, passado e futuro, 
e sobre a generalização de leitura de sentenças construídas com esses tempos verbais.

\section{Método}

\section{Participantes}

Vinte e um escolares de ambos os sexos, com a idade variando entre 7 e 9 anos, que frequentavam o $2^{\circ}$ e $3^{\circ}$ ano do Ensino Fundamental de uma escola da cidade do interior do Paraná foram submetidos a um teste de leitura de palavras e sentenças. Dentre os 21 escolares, oito não atingiram o critério de seleção no teste de repertório de entrada, que era não errar mais do que $20 \%$ do teste de leitura de palavras e errar mais do que $50 \%$ do teste de leitura das sentenças. Dos 13 escolares restantes, três não foram selecionados devido à incompatibilidade entre os horários das sessões experimentais e os horários de aula. Dos 10 escolares restantes, dois não concluíram todas as etapas do procedimento, um devido ao excesso de faltas às sessões e o outro porque necessitou de um número elevado de repetições das etapas de ensino, não tendo sido possível concluir todas as etapas antes do encerramento do ano letivo.

A presente pesquisa foi aprovada elo Comitê de Ética em Pesquisa da Universidade Estadual de Londrina (Processo no 083/10). Os pais e/ou responsáveis pelos participantes assinaram o Termo de Consentimento Livre e Esclarecido.

\section{Materiais e Local}

Foram utilizados um notebook, com monitor de 15; o programa PROLER (Assis \& Santos, 2010), elaborado em linguagem Visual Basic $6{ }^{\circledR}$, para a apresentação das tarefas de MTS e as de encadeamento; um fone de ouvido para os blocos que continham estímulos auditivos e um mouse para a entrada de dados.

Para o teste do repertório prévio de leitura, foram usados cartões com as palavras e as sentenças impressas (uma em cada cartão). As letras das palavras eram maiúsculas, na cor preta, no formato Times New Roman e com tamanho 20; as sentenças tinham a primeira letra maiúscula, estavam impressas em preto, no formato Times New Roman e com tamanho 14. Os estímulos usados nas atividades feitas no computador eram 24 figuras coloridas correspondendo às palavras de ensino (avó, avós, bebê, bebês, bexiga, bexigas, bolo, bolos, boné, bonés, camisa, camisas, homem, homens, maçã, maçãs, menina, meninas, menino, meninos, mulher, mulheres, pão e pães) e 36 animações em formato "gif" (ver exemplos de ilustrações das animações na Figura 1), referentes às sentenças (ver Tabela 1). As sentenças eram formadas por um artigo, um sujeito, um verbo e um objeto direto, o qual era composto por um numeral e um substantivo. Como consequências a serem apresentadas na tela do computador foram usadas animações gráficas, em formato "gif", com as imagens de personagens de histórias e desenhos infantis (e.g., princesas da Disney, Ben 10).
Tabela 1. Listas de sentenças do ensino das relações condicionais e dos testes das relações emergentes (coluna da esquerda) e sentenças de generalização da Etapa 4 (coluna da direita)

\begin{tabular}{|c|c|}
\hline Sentenças de Ensino e de Testes & Sentenças de Generalização \\
\hline $\begin{array}{l}\text { Dois bebês têm dois bonés. } \\
\text { Dois bebês tinham dois bonés. } \\
\text { Dois bebês terão dois bonés. }\end{array}$ & $\begin{array}{l}\text { Uma menina tem um boné. } \\
\text { Uma menina tinha um boné. } \\
\text { Uma menina terá um boné }\end{array}$ \\
\hline $\begin{array}{l}\text { Um menino tem três bexigas. } \\
\text { Um menino tinha três bexigas. } \\
\text { Um menino terá três bexigas. }\end{array}$ & $\begin{array}{l}\text { Três bebês têm duas bexigas. } \\
\text { Três bebês tinham duas bexigas. } \\
\text { Três bebês terão duas bexigas. }\end{array}$ \\
\hline $\begin{array}{l}\text { Três avós comem uma maçã. } \\
\text { Três avós comeram uma maçã. } \\
\text { Três avós comerão uma maçã. }\end{array}$ & $\begin{array}{l}\text { Dois homens cortam um pão. } \\
\text { Dois homens cortaram um pão. } \\
\text { Dois homens cortarão um pão. }\end{array}$ \\
\hline $\begin{array}{l}\text { Uma mulher vende duas camisas. } \\
\text { Uma mulher vendeu duas camisas. } \\
\text { Uma mulher venderá duas camisas. }\end{array}$ & $\begin{array}{l}\text { Duas mulheres compram três } \\
\text { camisas. } \\
\text { Duas mulheres compraram três } \\
\text { camisas. } \\
\text { Duas mulheres comprarão três } \\
\text { camisas. }\end{array}$ \\
\hline $\begin{array}{l}\text { Duas meninas compram três pães. } \\
\text { Duas meninas compraram três pães. } \\
\text { Duas meninas comprarão três pães }\end{array}$ & $\begin{array}{l}\text { Um menino come uma maçã. } \\
\text { Um menino comeu uma maçã. } \\
\text { Um menino comerá uma maçã. }\end{array}$ \\
\hline $\begin{array}{l}\text { Três homens cortam um bolo. } \\
\text { Três homens cortaram um bolo. } \\
\text { Três homens cortarão um bolo. }\end{array}$ & $\begin{array}{l}\text { Três avós vendem dois bolos. } \\
\text { Três avós venderam dois bolos. } \\
\text { Três avós venderão dois bolos. }\end{array}$ \\
\hline $\begin{array}{l}\text { Um bebê tem um boné. } \\
\text { Um bebê tinha um boné. } \\
\text { Um bebê terá um boné. }\end{array}$ & $\begin{array}{l}\text { Dois bebês comem um bolo. } \\
\text { Dois bebês comeram um bolo. } \\
\text { Dois bebês comerão um bolo. }\end{array}$ \\
\hline $\begin{array}{l}\text { Três meninos têm três bexigas. } \\
\text { Três meninos tinham três bexigas. } \\
\text { Três meninos terão três bexigas. }\end{array}$ & $\begin{array}{l}\text { Uma menina tem uma bexiga. } \\
\text { Uma menina tinha uma bexiga. } \\
\text { Uma menina terá uma bexiga. }\end{array}$ \\
\hline $\begin{array}{l}\text { Duas avós comem duas maçãs. } \\
\text { Duas avós comeram duas maçãs. } \\
\text { Duas avós comerão duas maçãs. }\end{array}$ & $\begin{array}{l}\text { Três avós têm dois pães. } \\
\text { Três avós tinham dois pães. } \\
\text { Três avós terão dois pães. }\end{array}$ \\
\hline $\begin{array}{l}\text { Duas mulheres vendem três camisas. } \\
\text { Duas mulheres venderam três camisas. } \\
\text { Duas mulheres venderão três camisas. }\end{array}$ & $\begin{array}{l}\text { Duas mulheres cortam duas maçãs. } \\
\text { Duas mulheres cortaram duas maçãs. } \\
\text { Duas mulheres cortarão duas maçãs. }\end{array}$ \\
\hline $\begin{array}{l}\text { Três meninas compram um pão. } \\
\text { Três meninas compraram um pão. } \\
\text { Três meninas comprarão um pão. }\end{array}$ & $\begin{array}{l}\text { Três meninos vendem um boné. } \\
\text { Três meninos venderam um boné. } \\
\text { Três meninos venderão um boné. }\end{array}$ \\
\hline $\begin{array}{l}\text { Um homem corta dois bolos. } \\
\text { Um homem cortou dois bolos. } \\
\text { Um homem cortará dois bolos. }\end{array}$ & $\begin{array}{l}\text { Um homem compra três bolos. } \\
\text { Um homem comprou três bolos. } \\
\text { Um homem comprará três bolos. }\end{array}$ \\
\hline
\end{tabular}

As sessões foram realizadas nas dependências da escola, em uma sala cedida pela direção do estabelecimento, com reduzida estimulação auditiva e visual estranha ao procedimento.

\section{Procedimento}

O procedimento foi composto por seis etapas, cada uma com um número específico de blocos, variando de um a 15 blocos. Cada sessão tinha duração aproximada de 20 minutos, sendo realizada durante os dias letivos da semana, porém sem dias fixos de coleta de dados. Na Etapa 1, os participantes foram submetidos a um teste do repertório prévio de leitura (Pré-teste) composto de 10 palavras e 10 sentenças e, na Etapa 6, a um Pós-teste composto por 10 palavras, cinco sentenças de ensino e cinco de generalização. Nas Etapas 2, $3,4,5$ foram realizados, respectivamente, treino e teste das relações condicionais entre palavra falada, palavra impressa e 


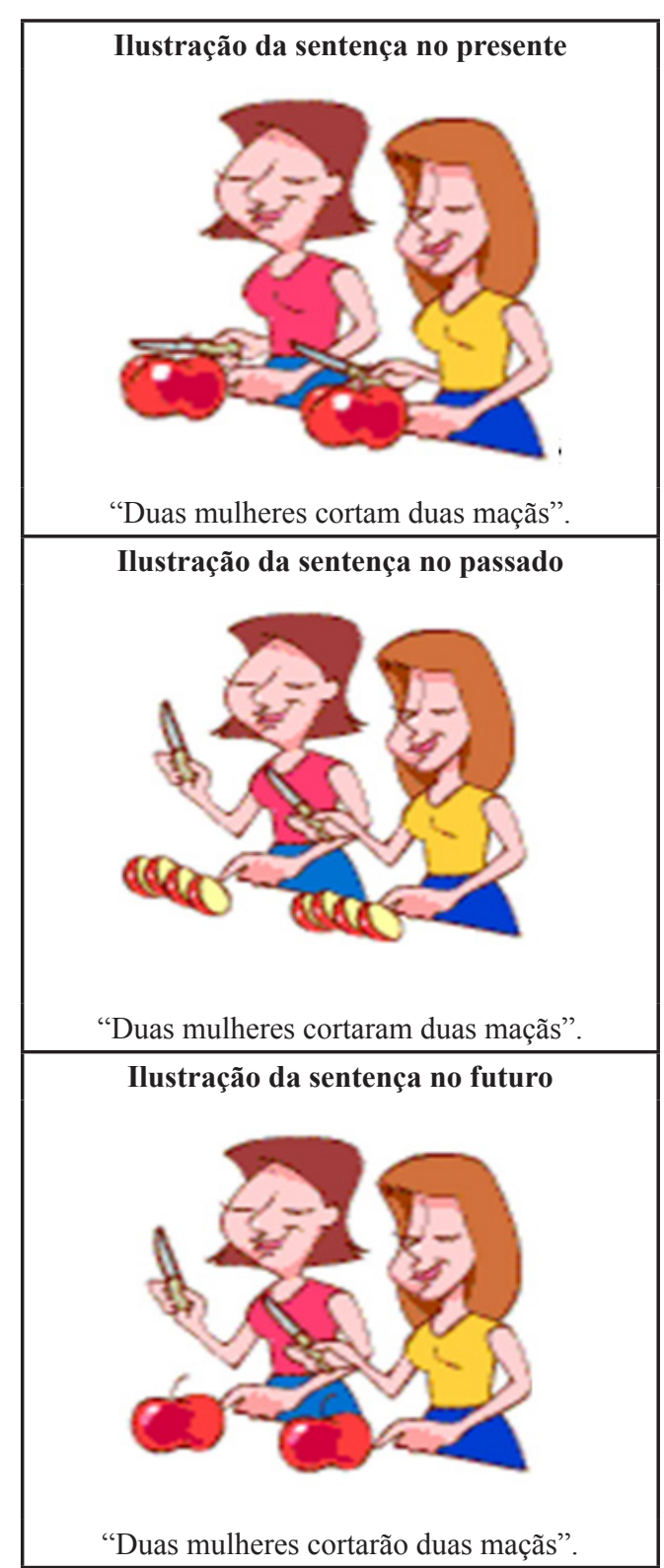

Figura 1. Ilustrações correspondentes às animações usadas como estímulos-modelo ou de comparação nas tentativas de teste e de ensino do MTS.

figura; treino e teste de ordenação das palavras das sentenças; teste de conectividade; treino e teste de relações condicionais entre sentenças faladas, sentenças escritas e animações. $\mathrm{Na}$ Tabela 2 está a distribuição das etapas e dos blocos de ensino e de teste, bem como a especificação dos estímulos-modelo, das repostas/escolhas nas tentativas de MTS ou tarefas de cada bloco.

No treino, as respostas corretas produziram consequências liberadas pelo programa de computador na forma de animação gráfica, com imagens de personagens de histórias e desenhos infantis (e.g., princesas da Disney, Ben 10) e simultaneamente eram apresentadas, pela experimentadora, expressões verbais, como "Muito bem!", "Continue assim!", "Parabéns!" etc. Após cada resposta incorreta, a tela do computador era escurecida por $2 \mathrm{~s}$ e nenhuma expressão verbal era liberada. Após a liberação das consequências das respostas corretas e incorretas, uma nova tentativa era iniciada. Ou seja, uma tentativa nunca era repetida, mesmo no caso de erro, em todas as etapas do procedimento.

$\mathrm{O}$ critério de acertos utilizado nas etapas era de três respostas corretas não consecutivas de cada relação condicional apresentada, com exceção das Etapas 1 e 6. Caso o participante não atingisse esse critério em um bloco de treino, ele era submetido novamente ao mesmo bloco de treino. Caso o participante não atingisse o critério de acerto em um bloco de teste no final da etapa, ele era submetido novamente a toda a etapa de ensino.

\section{Etapa 1- Teste do Repertório Prévio de Leitura (Pré- teste)}

O Pré-teste teve como objetivo selecionar os participantes do estudo e avaliar o repertório prévio de leitura, sendo composto por 10 palavras e 10 sentenças. As palavras continham dificuldades da língua, como monossílabos, dissílabos e trissílabos, com dígrafos, com acentos agudos e com sílabas formadas com letras cujo grafema e fonema não correspondem (e.g., "S" com som de "Z"). O participante era solicitado a ler em voz alta as seguintes palavras: pães, compraram, maçãs, têm, mulher, bexigas, venderá, bonés, cortará e camisas. Em seguida, era solicitado a ler as seguintes sentenças: (a) Três homens cortam um bolo; (b) Uma mulher vende duas camisas, (c) Duas avós comeram duas maçãs, (d) Três avós comeram uma maçã, (e) Três meninas comprarão um pão, (f) Um menino tinha três bexigas, ( $g$ ) Um bebê terá um boné, (h) Duas meninas compraram três pães, (i), Duas mulheres venderão três camisas e (j) Dois bebês terão dois bonés. Esses estímulos foram apresentados em cartões individuais e fizeram parte do procedimento de ensino subsequente feito por meio do computador.

\section{Etapa 2- Ensino de Relações Condicionais e Teste das Relações Emergentes}

Todos os participantes foram submetidos ao ensino de relações condicionais entre: palavra ditada (A) e repetição da palavra (B) - relações AB; palavra ditada (A) e palavras impressas (C) - relação AC; palavra impressa (C) e montagem da palavra com letras (D) - relação CD. O ensino era realizado por meio do procedimento de MTS, em sessões individuais. O estímulo-modelo era apresentado no centro da tela e o participante era instruído a selecionar, dentre três estímulos de comparação, aquele que correspondia ao estímulo-modelo.

No Treino 2.1, era dada a seguinte instrução a cada um dos participantes:

Você verá um quadrado contendo um símbolo de uma nota musical no centro da tela (a experimentadora apontava com o dedo o local onde o estímulo-modelo iria aparecer - "área de escolha"). Você deverá clicar nesta nota musical, em seguida, deverá repetir a palavra que você ouviu.

No Treino 2.2, era dada a seguinte instrução: 
Tabela 2. Sequência de etapas e dos blocos de ensino e de teste, e especificação dos estímulosmodelo, das repostas/escolhas nas tentativas de MTS ou tarefas de cada bloco

\begin{tabular}{|c|c|c|c|}
\hline \multirow{3}{*}{ 荧 } & Bloco de Testes & & \\
\hline & \multirow{2}{*}{ Pré-teste } & \multicolumn{2}{|c|}{ Leitura de dez palavras } \\
\hline & & \multicolumn{2}{|c|}{ Leitura de dez Sentenças } \\
\hline \multirow{10}{*}{ 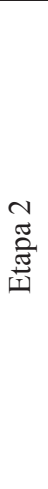 } & Blocos de treino & Estímulos-modelo & Respostas/escolhas \\
\hline & 2.1 & Palavras ditadas & Nomeação \\
\hline & 2.2 & Palavras ditadas & Palavra impressa \\
\hline & 2.3 & Palavra impressa & Construção de palavra com letras \\
\hline & Blocos de teste & Estímulos-modelo & Respostas/escolhas \\
\hline & 2.4 & Palavra impressa & Nomeação \\
\hline & 2.5 & Palavra impressa & Figura \\
\hline & 2.6 & Figura & Palavra impressa \\
\hline & 2.7 & Palavra ditada & Construção de palavra com letras \\
\hline & 2.8 & Figura & Construção de palavra com letras \\
\hline \multirow{6}{*}{ 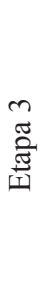 } & Blocos de treino & \multicolumn{2}{|c|}{ Tarefas } \\
\hline & 3.1 & \multicolumn{2}{|c|}{ Encadeamento de palavras (Construção de sentenças no passado) } \\
\hline & 3.2 & \multicolumn{2}{|c|}{ Encadeamento de palavras (Construção de sentenças no presente) } \\
\hline & 3.3 & \multicolumn{2}{|c|}{ Encadeamento de palavras (Construção de sentenças no futuro) } \\
\hline & Bloco de teste & \multicolumn{2}{|c|}{ Tarefa } \\
\hline & 3.4 & \multicolumn{2}{|c|}{ Construção de sentenças de ensino (misto: passado, presente e futuro) } \\
\hline \multirow{2}{*}{ 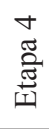 } & Bloco de teste & \multicolumn{2}{|c|}{ Tarefa } \\
\hline & $\begin{array}{c}\text { Teste de } \\
\text { conectividade }\end{array}$ & \multicolumn{2}{|c|}{ Construção de sentenças inéditas (misto: passado, presente e futuro) } \\
\hline \multirow{17}{*}{ 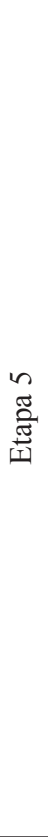 } & Blocos de treino & Estímulos-modelo & Respostas/escolhas \\
\hline & 5.1 & Sentença ditada (passado) & Animação (passado) \\
\hline & 5.1 & Sentença ditada (presente) & Animação (presente) \\
\hline & 5.3 & Sentença ditada (futuro) & Animação (futuro) \\
\hline & 5.4 & Sentença ditada (passado) & Sentença impressa (passado) \\
\hline & 5.5 & Sentença ditada (presente) & Sentença impressa (presente) \\
\hline & 5.6 & Sentença ditada (futuro) & Sentença impressa (futuro) \\
\hline & Blocos de teste & Estímulos-modelo & Respostas/escolhas \\
\hline & 5.7 & Animação (passado) & Sentença impressa (passado) \\
\hline & 5.8 & Animação (presente) & Sentença impressa (presente) \\
\hline & 5.9 & Animação (futuro) & Sentença impressa (futuro) \\
\hline & 5.10 & Sentença impressa (passado) & Animação (passado) \\
\hline & 5.11 & Sentença impressa (presente) & Animação (presente) \\
\hline & 5.12 & Sentença impressa (futuro) & Animação (futuro) \\
\hline & 5.13 & Sentença impressa (passado) & Leitura (passado) \\
\hline & 5.14 & Sentença impressa (presente) & Leitura (presente) \\
\hline & 5.15 & Sentença impressa (futuro) & Leitura (futuro) \\
\hline \multirow{3}{*}{ 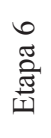 } & Bloco de teste & \multicolumn{2}{|c|}{ Tarefas } \\
\hline & Pós_teste & \multicolumn{2}{|c|}{ Leitura de 10 palavras } \\
\hline & 1 OS-LSt & \multicolumn{2}{|c|}{ Leitura de cinco sentenças de ensino e cinco de generalização } \\
\hline
\end{tabular}


Você verá um quadrado contendo uma palavra no centro da tela (a experimentadora apontava com o dedo o local onde o estímulo-modelo iria aparecer). Assim que você clicar no quadrado do centro, irão aparecer três outros quadrados. Nesses quadrados aparecerão palavras. Eu gostaria que você clicasse com o mouse naquele quadrado que você achar que corresponde ao quadrado do centro.

No Treino 2.3, era dada a seguinte instrução:

Você verá um quadrado contendo uma palavra no centro da tela (a experimentadora apontava a área de construção). Assim que você clicar no quadrado do centro, aparecerão letras na parte de baixo (a experimentadora apontava para a área de escolha). Eu gostaria que você clicasse com o mouse sobre as letras que formam a palavra apresentada.

Cada bloco dos Treinos 2.1, 2.2 e 2.3 era formado por quatro conjuntos de 12 tentativas que envolviam quatro vezes cada uma das três relações condicionais a serem treinadas.

Após o ensino de cada uma das relações condicionais, foram testadas as relações condicionais: palavra impressa e nomeação da palavra - relações $\mathrm{CB}$; palavra impressa e figura - relações CE; figura e palavra impressa - relações EC; palavra ditada e montagem das palavras com letras - relações AD; figura e a montagem de palavras com letras - relações ED. Cada uma dessas relações condicionais era apresentada, de maneira aleatória, quatro vezes, o que compunha um conjunto com 12 classes de estímulos. Cada conjunto era apresentado quatro vezes.

Durante os testes, as respostas de escolha da palavra correta ou nomeação correta da palavra não produziam as consequências programadas. As instruções dadas para todos os participantes nos blocos de testes eram: Continue fazendo como antes, porém agora não irão aparecer mais as figurinhas [as consequências] e eu não vou dizer se você está acertando ou não. Se o participante cometesse mais de um erro em uma das relações condicionais no teste, o procedimento de ensino era repetido desde o começo da etapa correspondente. Caso atingisse o critério de acerto, iniciava-se a etapa de treino seguinte (Etapa 3).

\section{Etapa 3- Ensino de Sentenças por Encadeamento e Teste de Formação das Sentenças}

Nessa etapa, era ensinado e testado o encadeamento das 36 sentenças impressas formadas por cinco palavras (ver coluna da esquerda da Tabela 1). Foram ensinadas, inicialmente, as sentenças no tempo verbal passado, depois no presente e, finalmente, as sentenças no tempo futuro. O procedimento de encadeamento consistiu em apresentar as palavras que compunham uma sentença na "área de escolha", localizada na parte inferior da tela, com ampliação gradual do número de palavras, conforme descrito a seguir. Os participantes deveriam clicar com o mouse sobre as palavras em sequência, sendo elas deslocadas para a "área de construção", localizada na parte superior da tela, à medida que eram escolhidas. A instrução dada a cada participante era:

Agora, você verá um grande retângulo aqui em cima (a experimentadora apontava para área de construção); sua tarefa é escrever uma frase. Cada palavra que compõe essa frase vai aparecer aqui embaixo (a experimentadora apontava para a área

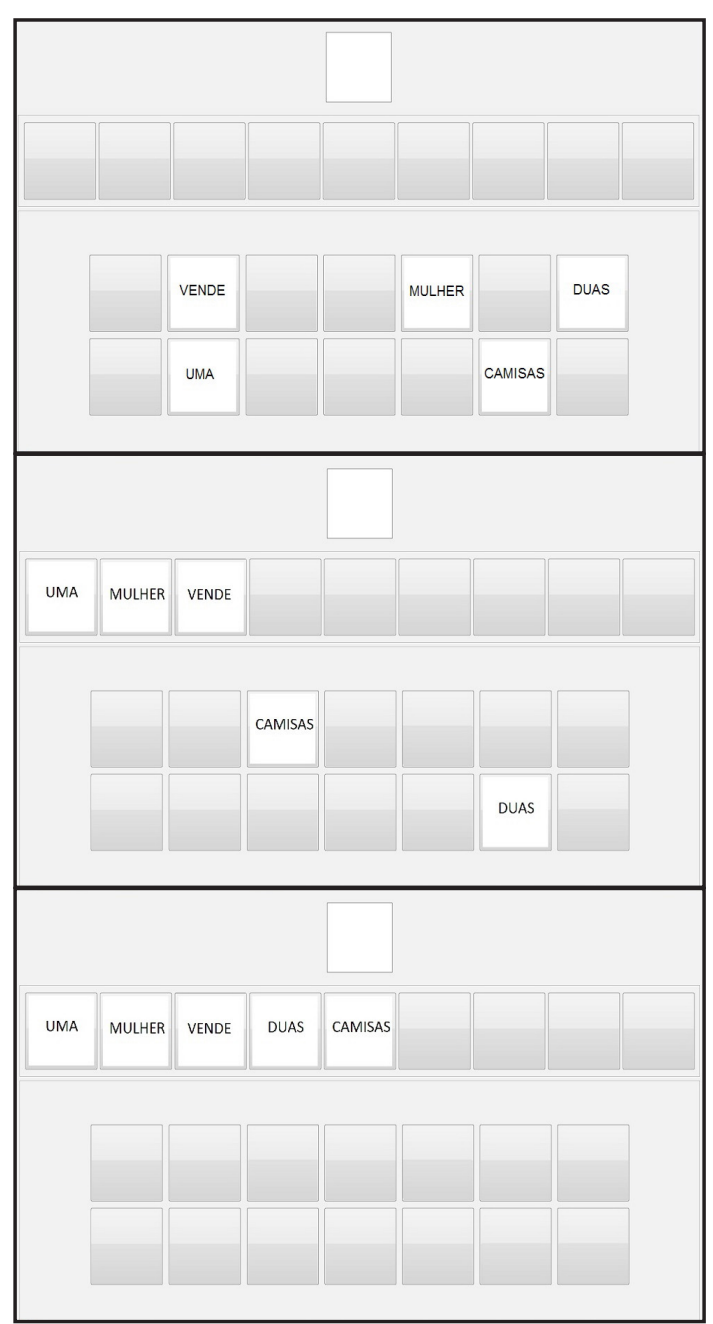

Figura 2. Telas vistas pelo participante na construção de uma sentença. A tela superior corresponde ao início da tentativa em que nenhuma escolha foi feita; a tela do centro corresponde à tentativa em que três palavras foram escolhidas; a tela inferior corresponde à conclusão da tarefa.

de escolha). Você deverá clicar na(s) palavra(s) que forma $(\mathrm{m})$ a frase na ordem correta. Preste atenção, pois você não poderá voltar atrás depois que clicar com o mouse em uma palavra.

$\mathrm{O}$ número de palavras que formavam uma sentença era aumentado gradualmente. Na tentativa inicial, era apresentada apenas a palavra correta, garantindo o acerto. Depois as palavras eram acrescentadas uma a uma, até que todas as palavras que compunham a sentença aparecessem simultaneamente e em ordem aleatória na área de escolha. Uma escolha incorreta em qualquer parte da cadeia que formava a sentença era considerada um erro. A Figura 2 apresenta um exemplo de construção de uma sentença com partes das telas vistas pelo participante em uma tentativa.

Após o ensino de cada sentença, iniciando com uma palavra e terminando com cinco palavras, era feito um teste. Nesse teste, o participante devia escolher as palavras na sequência, não ocorrendo consequências quando a sentença era completada. Após cada tentativa de teste, havia a introdução imediata de um novo conjunto de estímulos 
(palavras), caracterizando uma tentativa nova. No Teste 3.4, todas as palavras que formavam a sentença de ensino eram apresentadas simultaneamente na área de escolha. A seguinte instrução era dada para cada participante:

Você verá cinco palavras aqui nessa parte da tela (experimentadora apontava para parte a qual ela estava se referindo). Sua tarefa é selecionar uma palavra de cada vez para formar uma sentença. Preste atenção, pois você não poderá voltar atrás depois que clicar com o mouse em uma palavra. Não aparecerão as figurinhas no final de cada exercício e eu não falarei se você acertou o exercício.

\section{Etapa 4 - Teste de Conectividade}

Esse teste consistiu em apresentar cinco palavras (um artigo, um sujeito da oração, um verbo e um objeto direto formado por duas palavras) de diferentes sentenças e diferentes tempos verbais, mas mantendo a concordância verbo-nominal. Esses estímulos eram apresentados simultaneamente na área de escolha e a tarefa do participante consistia em montar as sentenças novas (ver coluna da direita da Tabela 1). Essa etapa era composta por 48 tentativas que correspondiam a 12 sentenças, quatro sentenças de cada tempo verbal (passado, presente e futuro), apresentadas em ordem aleatória. O Teste de Conectividade se assemelha ao Teste 3.4. O participante era solicitado a escolher, uma a uma, as cinco palavras apresentadas na área de escolha. Cada palavra selecionada com o mouse era automaticamente deslocada para área de construção. A seguinte instrução era dada a cada participante:

Você verá cinco palavras aqui nessa parte da tela (experimentadora apontava para parte a qual ela estava se referindo), sua tarefa é selecionar uma palavra de cada vez para formar uma sentença. Preste atenção, pois você não poderá voltar atrás depois que clicar com o mouse em uma palavra. Não aparecerão as figurinhas no final de cada exercício e eu não falarei se você acertou o exercício.

\section{Etapa 5 - Ensino das Relações Condicionais entre Sentenças Faladas, Sentenças Escritas e Animações}

Nessa etapa, era aplicado um procedimento de MTS em que uma sentença falada era apresentada com estímulomodelo e as animações referentes aos diferentes tempos verbais da mesma sentença eram apresentados como estímulos de comparação (Treino AB). Eram apresentados três conjuntos de 12 sentenças em ordem aleatória: um conjunto formado por sentenças no passado, um formado por sentenças no futuro e um por sentenças no presente. Cada conjunto de 12 tentativas era apresentado quatro vezes. Assim, o número total de tentativas era 144.

Em seguida, era ensinada a relação entre sentença ditada e sentença impressa (Treino AC), também com 144 tentativas ao todo. O participante deveria responder corretamente três tentativas alternadas para atingir o critério de acerto e ser exposto aos testes das relações emergentes entre: animação e sentença impressa (BC), que correspondem aos Testes
5.7, 5.8, 5.9; sentença impressa e animação (CB), que correspondem aos Testes 5.10, 5.11, 5.12; sentença impressa e leitura (CD), que correspondem aos Testes 5.13, 5.14, 5.15. A instrução dada para todos os participantes era semelhante às instruções dadas nos testes da Etapa 2.

\section{Etapa 6 - Pós-teste}

Nessa etapa, era aplicado um teste de leitura, contendo 10 palavras (pães, compraram, maçãs, têm, mulher, bexigas, venderá, bonés, cortará e camisas) e 10 sentenças (Três homens cortam um bolo; Uma mulher vende duas camisas; Duas avós comerão duas maçãs; Três avós comeram uma maçã; Três meninas comprarão um pão; Um menino tinha três bexigas; Um bebê terá um boné; Duas meninas compraram três pães; Duas mulheres venderão três camisas; Dois bebês terão dois bonés), das quais seis eram sentenças de generalização.

\section{Resultados}

O desempenho foi medido em termos do número de vezes que o participante foi submetido à apresentação dos blocos de treino e da porcentagem de acertos nos treinos e testes de cada etapa do procedimento.

Quanto ao número de blocos de treino e de teste, na Etapa 2, a maioria dos participantes realizou apenas uma vez cada um deles. O participante P04 repetiu uma vez o Treino 2.2, referente ao ensino da relação entre palavra ditada e palavra impressa. Os participantes P01, P02 e P08 tiveram que ser expostos novamente a toda a sequência do procedimento na Etapa 2: P01, duas vezes, e P02 e P08, uma vez. Esse retorno foi realizado porque $\mathrm{P} 01$ não atingiu o critério de acertos no teste da relação entre palavras impressas e nomeação, na primeira vez que realizou o Teste 2.4. Esse participante, assim como P02 e P08, também não atingiu o critério no teste da relação emergente entre palavras ditadas e construção de palavras (Teste 2.7). Na Etapa 3 (treino e teste de encadeamento de sentenças) e na Etapa 5 (relações condicionais com sentenças e animações), todos os participantes atingiram o critério de acertos na primeira exposição aos blocos, não sendo reexpostos a qualquer bloco.

$\mathrm{Na}$ Figura 3 estão registradas as porcentagens de acertos de leitura das 10 palavras do Pré-teste (Etapa 1), das palavras do teste de leitura com compreensão de palavras (Etapa 2, média dos Teste 2.4, Teste 2.5, Teste 2.6) e das 10 palavras do Pós-teste (Etapa 6). Nessa figura, pode-se verificar que todos os participantes apresentaram porcentagens de acertos acima de $90 \%$ no teste de leitura com compreensão de palavras, após terem sido submetidos ao procedimento de ensino das relações condicionais. Esse desempenho era o critério para passar para a etapa seguinte. Os participantes P06 e P07 P07 apresentaram as maiores diferenças nas porcentagens de acertos na leitura das palavras ao se comparar os resultados do Pré-teste com os do Pós-teste. Esses participantes leram $20 \%$ das 10 palavras apresentadas no Pré-teste e $70 \%$ das 10 palavras do Pós-teste. O participante P02 apresentou a 
menor diferença $(10 \%)$ entre o resultado do Pré-teste e o do Pós-teste de leitura de palavras. Quatro participantes (P01, P03, P04, P08) atingiram porcentagens iguais ou superiores a $90 \%$ de acertos no Pós-teste.

$\mathrm{Na}$ Figura 4 estão as porcentagens médias de acertos nos testes das relações condicionais entre animação e sentença

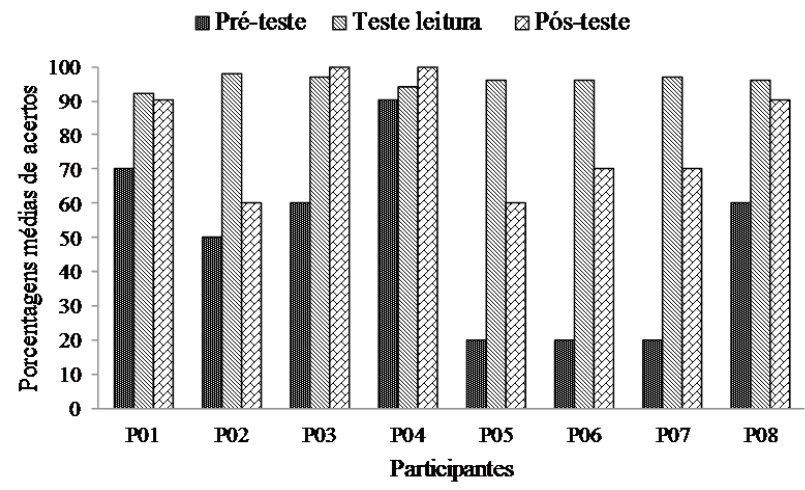

Figura 3. Porcentagens médias de acertos de leitura de palavras no Pré-teste (Etapa 1), no teste de leitura com compreensão (Etapa 2) e no Pós-teste (Etapa 6).

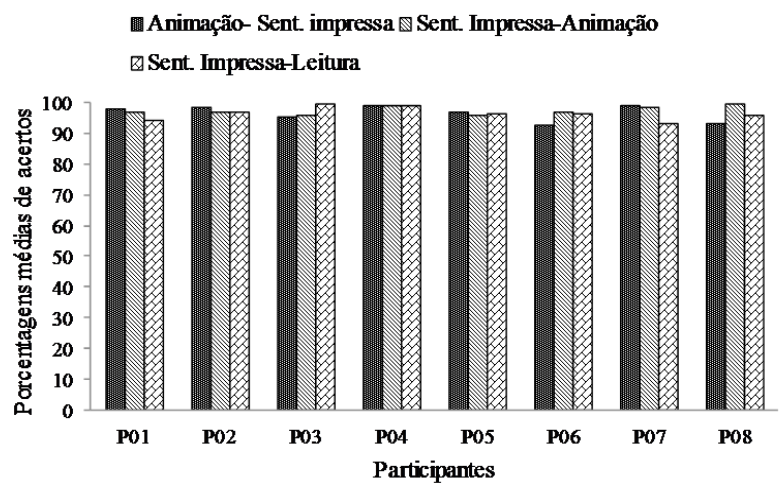

Figura 4. Porcentagens médias de acertos nos testes das relações condicionais entre animação-sentença impressa (Testes 5.7, 5.8, 5.9), sentença impressa-animação (Testes 5.10, 5.11, 5.12), e sentença impressa-leitura (Testes 5.13, 5.14, 5.15)..

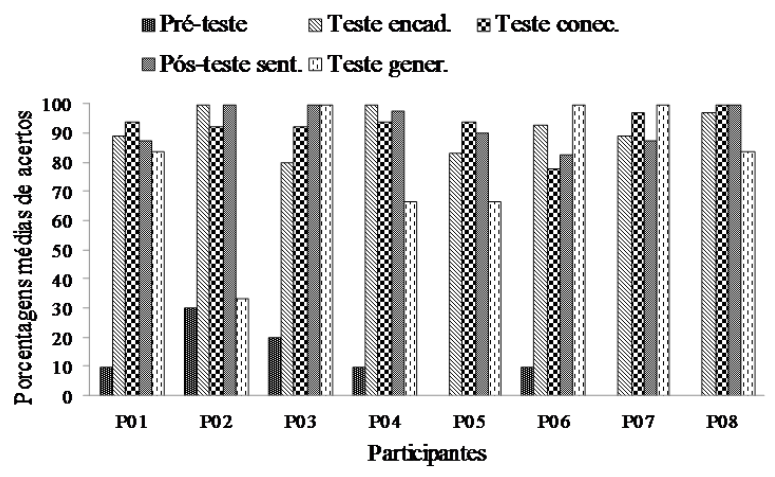

Figura 5. Porcentagens de acertos de leitura de sentenças no Préteste (Etapa 1), no Teste de encadeamento (Teste 3.4 ), no Teste de conectividade (Etapa 4), no Pós-teste de leitura de sentenças (Etapa 6) e no Teste de generalização (também realizado na Etapa 6). impressa (Testes 5.7, 5.8, 5.9), sentença impressa e animação (Testes 5.10, 5.11, 5.12), e sentença impressa e leitura (Testes $5.13,5.14,5.15)$. Verifica-se que todos os participantes atingiram porcentagens altas de acertos, com valores variando de 93,5 a 100\% de acertos. Quatro dos oito participante (P01, P02, P05 e P07) apresentaram porcentagens um pouco maiores nas tentativas que envolviam relação entre animação e sentença impressa do que entre sentença impressa e leitura, mas essa diferença foi de, no máximo, 5,8\%, no caso do P07.

A análise em separado dos dados das sentenças no presente, passado e futuro revelou que não houve grande diferença ao se considerar o tempo verbal, pois os oito participantes apresentaram mais de $90 \%$ de acertos nos testes da Etapa 5. A porcentagem média de acertos nos testes das relações condicionais Animação/Sentença Impressa, Sentença Impressa/Animação e Sentença Impressa/Leitura variou de $95,6 \%$ a $97 \%$, diante das sentenças no presente; de 96,65 a 98,7\%, diante das sentenças no passado; e de $96,3 \%$ a $97,4 \%$, diante das sentenças no futuro.

\section{Discussão}

O objetivo do presente estudo foi o de investigar o efeito de uma sequência de blocos de ensino e de testes de relações condicionais, e do encadeamento de palavras sobre a leitura com compreensão das sentenças no presente, passado e futuro. Para atingir esse objetivo, inicialmente procurou-se garantir que as palavras a serem encadeadas para formar as sentenças fossem lidas com compreensão pelos escolares, pois com base na demonstração feita por Sampaio et al. (2010), a leitura com compreensão de sentenças depende da leitura com compreensão das palavras que compõem as sentenças. Os resultados obtidos permitem afirmar que todos os participantes formaram as classes equivalentes envolvendo as palavras, demonstrando leitura com compreensão, uma vez que todos concluíram o procedimento de ensino, atingindo o critério de acertos de cada bloco da Etapa 2.

Alguns participantes não apresentaram a emergência das relações equivalentes entre palavra impressa, palavra falada e figura na primeira exposição ao treino, sendo necessário expô-los mais vezes ao treino das relações condicionais. Green e Saunders (1998) apontam que, em alguns casos, a emergência de relações equivalentes nem sempre ocorre na primeira exposição, podendo ocorrer de maneira gradual. Apesar da necessidade de reexposição a alguns blocos de ensino e de teste, pode-se afirmar que o procedimento de MTS foi efetivo para que as relações equivalentes fossem estabelecidas.

Em relação ao procedimento que promoveu a leitura com compreensão das palavras, deve-se considerar, ainda, que o desempenho inicial da maioria dos participantes na leitura textual de palavras não era muito baixo. A maioria dos participantes acertou mais de $50 \%$ (com exceção de três que acertaram 20\%), o que provavelmente contribuiu para que não se necessitasse de reexposição aos blocos de treino.

Após terem atingido o critério de acertos no treino discriminativo, que promoveu a leitura com compreensão das unidades que compõem as sentenças, os participantes foram expostos às Etapas 3 e 4, em que foi feito o treino de 
encadeamento das palavras para a formação das sentenças e o teste de conectividade envolvendo a formação de sentenças inéditas. Os resultados desses testes permitem concluir que após o treino de encadeamento, realizado depois do treino de discriminação condicional que promoveu leitura com compreensão das palavras, os participantes demonstraram ser capazes de encadear as palavras para formar as sentenças de ensino e, em seguida, encadear as palavras para formar as sentenças inéditas. Esses resultados corroboram os de Sampaio et al. (2010), permitindo concluir que cada palavra adquiriu a função sintática das palavras das sentenças de ensino. Além disso, permite afirmar, conforme foi feito por Mackay, Stoddart e Spencer (1989), que as classes gramaticais das palavras tornam-se classes funcionais de estímulos com propriedades ordinais.

Segundo Assis et al. (2009), a estrutura sintática de uma sentença indica as relações que as palavras estabelecem umas com as outras para que a sentença tenha sentido e seja compreendida. Após estabelecer a função que exerce cada palavra em uma sentença, é possível formar novas classes sequenciais intercambiando as palavras da mesma classe. Um exemplo de intercâmbio das palavras de mesma classe, para formar uma nova sentença, observado no presente estudo, foi que após o ensino das sentenças "Uma mulher vende duas camisas" e "Duas meninas compram três pães", os participantes foram capazes de intercambiar as palavras, formando uma sentença inédita, como "Duas mulheres compram três camisas".

Por meio do teste de conectividade foi possível demonstrar que os participantes aprenderam as funções gramaticais das palavras, mas esse teste não é uma demonstração clara de que os participantes compreenderam o significado das sentenças. Para garantir esse desempenho, no presente estudo, foi aplicado, na Etapa 5, um procedimento semelhante ao que foi executado por Ponciano e Moroz (2012), em que o procedimento de treino de discriminações condicionais teve como unidades de ensino as sentenças. No estudo dessas autoras, as sentenças eram representadas por imagens e as sentenças eram formadas por: artigo + sujeito + verbo + complemento do verbo. Essas funções sintáticas eram representadas respectivamente por $(\mathrm{a}, \mathrm{o})+($ rato, gato, pato, arara, abelha, galinha, cão, coelho, macaco) + (está) + (na cama, na mesa, no sofá). Durante o treino foram apresentadas frases com variação de sujeito e frases com variação de complemento. No presente estudo, as sentenças eram representadas por animações em vez de imagens inanimadas e as sentenças eram formadas por numeral + substantivo + verbo (no presente, passado ou futuro)+ numeral+ objeto direto. A variação durante o treino era referente ao tempo verbal. Ambos os estudos contribuíram para que se observasse a leitura com compreensão das sentenças, sendo que, no presente estudo, todos os participantes apresentaram desempenhos superiores a $90 \%$ de acertos nos testes das relações emergentes que demonstram a formação de classes de equivalência entre sentenças impressas, animações e sentenças faladas (leitura).

Os resultados obtidos permitem concluir que o ensino de discriminações condicionais de palavras seguido pelo ensino de formação das sentenças por meio de encadeamento e o subsequente estabelecimento de equivalência de estímulos entre animações, sentenças faladas e sentenças impressas foram eficientes para estabelecer a leitura com compreensão tanto de sentenças no presente, quanto no passado e no futuro. Os resultados mostraram também que essa sequência de procedimentos foi eficaz para promover a generalização de leitura de sentenças inéditas nos três tempos verbais. Pode-se concluir ainda, que diferentes formas de ensino de sentenças com base nos princípios da Análise do Comportamento e no modelo da equivalência de estímulos podem produzir resultados positivos na aprendizagem de leitura de sentenças. Por exemplo, foram eficazes para o ensino de sentenças, os procedimentos de formação de classes ordinais com estabelecimento de controle de estímulos no responder sequencial (e.g., Corrêa et al., 2012; Sampaio et al., 2010), emergência de leitura de sentenças que não foram diretamente ensinadas por meio da formação de classes de equivalência (e.g., Ponciano \& Moroz, 2012) e leitura por agrupamento a partir do ensino prévio de classes de estímulos que compõem a sentenças, sem ter que ensiná-las diretamente (e.g., Medeiros et al., 2011).

Uma análise crítica e sistemática das diferenças metodológicas e conceituais dos diversos estudos da bibliografia da Análise do Comportamento poderia ser uma contribuição importante para o desenvolvimento de métodos de ensino de leitura de sentença e pesquisas futuras poderiam comparar variáveis de procedimentos com vistas a uma avaliação das diferenças nos resultados que cada um desses procedimentos produz. Outra linha promissora de investigação que também contribui para esclarecer as variáveis relevantes na compreensão de sentenças são os estudos desenvolvidos por de Souza e coautores (ver revisão em de Souza, Postalli \& Schmidt, 2013), que avaliaram a formação de controle instrucional por meio do modelo da equivalência de estímulos.

Para estudos futuros sugere-se que seja acrescentado um teste de montagem de sentenças entre as Etapas 2 e 3, para se ter uma linha de base do desempenho dos participantes com relação a essa habilidade. Sugere-se também que um Teste de Conectividade seja inserido antes do pós-teste, para avaliar a manutenção desse desempenho após os participantes terem sidos submetidos ao procedimento de ensino das relações condicionais com as animações. A inserção de mais testes de leitura, como os dos Blocos 5.13, 5.14 e 5.15 ao longo do procedimento também seria importante para demonstrar o processo de aquisição da leitura, ou seja, auxiliaria a identificação e controle de variáveis que poderiam interferir no desempenho dos participantes e, eventualmente, poderia contribuir para o aprimoramento do procedimento.

\section{Referências}

Assis, G. J. A., \& Costa, L. C. A. (2004). Emergência de relações ordinais em crianças. Interação em Psicologia, 8, 199-216.

Assis, G. J. A., \& Sampaio, M. E. C. (2003). Efeitos de dois procedimentos de ensino para formação de classes sequenciais. Interação em Psicologia, 7, 52-63.

Assis, G. J. A., \& Santos, M. B. (2010). PROLER (software sistema computadorizado para o ensino de comportamentos conceituais). Belém, PA: Universidade Federal do Pará. 
Assis, G. J. A., Baptista, M. Q. G., \& Nunes, A. L. de M. (2009). Formação de sequências: aspectos conceituais, metodológicos e questões de pesquisa. Interação em Psicologia, 13, 215-227.

Correa, D. R., Assis, G. J. A., \& Brino, A. L. F. (2012). Efeitos de sobreposição de palavras sobre a composição de sentenças sob controle condicional. Acta Comportamentalia, 20, 299-315.

de Rose, J. C, Souza, D. G., \& Hanna, E. S. (1996). Teaching reading spelling: Exclusion and stimulus equivalence. Journal of Applied Behavior Analysis, 29, 451-469. doi: 10.1901/ jaba.1996.29-451

de Souza, D. G., Postalli, L. M. M., \& Schmidt, A. (2013). Extending equivalence classes to sentences and to instruction following. European Journal of Behavior Analysis, 14, 105-116.

Green, G., \& Saunders, R. R. (1998). Stimulus equivalence. In K. Lattal \& M. Perone (Eds.), Handbook of research methods in human operant behavior (pp. 229-262). New York: Plenum.

Green, G., Stromer, R., \& Mackay, H. (1993). Relational learning in stimulus sequences. The Psychological Record, 43, 599-616.

Lima, M. P., \& Assis, G. J. A. (2003). Emergência de classes sequenciais após treino com pareamento consistente. Psicologia: Teoria e Pesquisa, 19, 75-84. doi: 10.1590/S010237722003000100010

Mackay, H. A., Stoddard, L. T., \& Spencer, T. J. (1989). Symbols and meaning classes: Multiple sequence production and the emergence of ordinal stimulus classes. Experimental Analysis of Human Behavior Bulletin, 7, 16-17.

Medeiros, J. G., Antunes, L., Pokreviescki, J. E. J., Bottenberg, D. G., Ferreira, C. A., \& Cavalhieri, K. E. (2011). Emergência de leitura de frases a partir do ensino de suas unidades constituintes. Acta Comportamentalia, 19, 317-342.
Nunes, A. L. M., \& Assis, G. J. A. (2006). Emergência de classes ordinais após o ensino de relações numéricas. Revista Brasileira de Análise do Comportamento, 2, 209-219.

Ponciano, V. L. de O., \& Moroz, M. (2012). Utilizando frases como unidade de ensino de leitura: um procedimento baseado na equivalência de estímulos. Revista Brasileira de Terapia Comportamental e Cognitiva, 14, 38-56.

Sampaio, M. E. C., \& Assis, G. J. A. (2005). Equivalência de estímulos sequenciais em portadores de necessidades educacionais especiais. Acta Comportamentalia, 13, 111-143.

Sampaio, M. E. C., Assis, G., \& Baptista, M. Q. G. (2010). Variáveis de procedimento de ensino e de testes na construção de sentenças com compreensão. Psicologia: Teoria e Pesquisa, 26, 145-155.

Sidman, M., \& Cresson, O. (1973). Reading and crossmodal transfer of stimulus equivalencies in severe mental retardation. American Journal of Mental Deficiency, 77, 515-523.

Souza, J. A. N., \& Assis, G. J. A. (2005). Efeito de dois procedimentos de ensino sobre o comportamento de ordenar. Psicologia em Estudo, 10, 527-536.

Souza, R. D. C., \& Assis, G. J. A. (2005). Emergência de relações numéricas em crianças surdas. Psicologia: Teoria e Pesquisa, 21, 297-308.

Stromer, R., Mackay, H. A., \& Stoddard, L. T. (1992). Classroom applications of stimulus equivalence technology. Journal of Behavioral Education, 2, 225-256.

Recebido em 21.04.2013

Primeira decisão editorial em 09.09.2013

Versão final em 21.10.2013

Aceito em 21.10.2013 